\title{
Hemispheric asymmetry in holistic processing of words
}

\author{
Paulo Ventura ${ }^{a}$, João Delgado ${ }^{a *}$, Miguel Ferreira ${ }^{a *}$, António Farinha- \\ Fernandes $^{\mathrm{a} *}$, José C. Guerreiro ${ }^{\mathrm{a} *}$, Bruno Faustino ${ }^{\mathrm{a} *}$, Isabel Leite ${ }^{\mathrm{b}}$ and Alan \\ C.-N. Wong ${ }^{c}$
}

${ }^{\mathrm{a}}$ Faculdade de Psicologia, Universidade de Lisboa, Alameda da Universidade, Lisboa, Portugal; ${ }^{b}$ Departamento de Psicologia, Universidade de Évora, Colégio Pedro da Fonseca, Parque Industrial e Tecnológico de Évora, Évora, Portugal; 'Department of Psychology, The Chinese University of Hong Kong, Shatin, N.T., Hong Kong

\begin{abstract}
Holistic processing has been regarded as a hallmark of face perception, indicating the automatic and obligatory tendency of the visual system to process all face parts as a perceptual unit rather than in isolation. Studies involving lateralized stimulus presentation suggest that the right hemisphere dominates holistic face processing. Holistic processing can also be shown with other categories such as words and thus it is not specific to faces or face-like expertize. Here, we used divided visual field presentation to investigate the possibly different contributions of the two hemispheres for holistic word processing. Observers performed same/different judgment on the cued parts of two sequentially presented words in the complete composite paradigm. Our data indicate a right hemisphere specialization for holistic word processing. Thus, these markers of expert object recognition are domain general.
\end{abstract}

ARTICLE HISTORY Received 1 February 2018; Accepted 4 May 2018

KEYWORDS Complete composite task; holistic word processing; divided visual field paradigm; hemispheric asymmetries; Portuguese words 